\title{
Trough Concentration Divided by Surface Area
}

National Cancer Institute

\section{Source}

National Cancer Institute. Trough Concentration Divided by Surface Area. NCI

Thesaurus. Code C102397.

The trough concentration divided by surface area. 